\title{
Anthropometric indices and their relationship with cardiometabolic risk factors in a sample of Turkish adults
}

\author{
Ahmet Selcuk Can ${ }^{1, *}$, Thomas P Bersot ${ }^{2}$ and Mithat Gönen ${ }^{3}$ \\ 'Department of Medicine, Istanbul Science University, Faculty of Medicine, Büyükdere Caddesi No. 120, \\ Esentepe, Șișli, 34394 Istanbul, Turkey: ${ }^{2}$ Gladstone Institute of Cardiovascular Disease and the University of \\ California, San Francisco, CA, USA: ${ }^{3}$ Department of Epidemiology and Biostatistics, Memorial Sloan-Kettering \\ Cancer Center, New York, NY, USA
}

Submitted 10 October 2007: Accepted 6 March 2008: First published online 19 May 2008

\begin{abstract}
Objective: To identify the best anthropometric index that predicts cardiometabolic risk factors.

Design and setting: Cross-sectional study in Turkey, in 2003.

Subjects: Turkish men and women aged 18 years and over $(n 1692)$ were examined. Body weight, height, waist and hip circumferences, blood pressure, total cholesterol, HDL cholesterol, TAG, glucose and insulin were measured. Metabolic syndrome score was calculated as the sum of modified National Cholesterol Education Program Adult Treatment Panel III criteria, excluding waist circumference. Insulin resistance was estimated by homeostasis model assessment (HOMA-IR).

Results: BMI, waist:hip ratio (WHpR), waist:height ratio (WHtR), waist circumference (WC) and hip circumference (HC) were significantly correlated with each other. Partial correlation coefficients between systolic blood pressure, HDL cholesterol, TAG levels or HOMA-IR and BMI, WC or WHtR were similar and higher than correlation coefficients of WHpR and HC. The association of anthropometric indices with metabolic syndrome score and Framingham risk score was highest for WHtR. Areas under the receiver-operating characteristic curves showed that WHtR was the best anthropometric index that discriminated between the presence and absence of hypertension, diabetes and metabolic syndrome, whereas WHpR was better for dyslipidaemia.

Conclusions: WHtR was the best anthropometric index for predicting most cardiometabolic risk factors. WC and BMI ranked second for their predictive capability of cardiometabolic risk, followed by WHpR and HC.
\end{abstract}

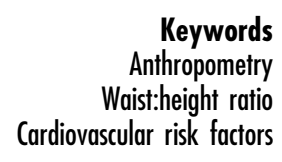

Anthropometric indices (anthropometrics) are a simple, safe and cost-free way to quantify the degree of obesity. Because of the lack of cheap and accurate methods for assessing body composition directly, anthropometrics are often used as surrogates for assessing obesity and body fat distribution. BMI is the most widely used anthropometric index and gives information on fat mass and lean mass $^{(1)}$. Measurement of waist circumference (WC) is recommended by the US National Cholesterol Education Program (NCEP) for the assessment of central obesity ${ }^{(2)}$, whereas the WHO recommends waist:hip ratio (WHpR) for the same purpose ${ }^{(1)}$. All of the mentioned anthropometric indices have been found to be associated with all-cause mortality, diabetes mellitus, cardiovascular morbidity and mortality in prospective studies ${ }^{(3-10)}$. Some authors have proposed waist:height ratio (WHtR) as the best anthropometric index to predict CVD risk and metabolic syndrome ${ }^{(11-14)}$. Hip circumference (HC) has been found to be inversely associated with diabetes, CVD morbidity and mortality in a prospective study ${ }^{(15)}$. The results of prospective and cross-sectional studies that have attempted to find the best anthropometric index are not uniform ${ }^{(3-22)}$. Studies from the Eastern Mediterranean area also do not agree on the best anthropometric index to predict cardiometabolic risk ${ }^{(23-29)}$. Work in Turkey has suggested that WHpR might better indicate CVD risk than BMI and $\mathrm{WC}^{(28,29)}$. Onat et al. ${ }^{(29)}$ showed that both WC and WHpR were strongly associated with BMI, age, diastolic blood pressure and plasma TAG, and WHpR was significantly associated with prevalent CHD only in Turkish women. Fasting glucose, insulin, HDL cholesterol (HDL-C) and LDL cholesterol (LDL-C) levels were not ascertained and the association of anthropometric indices with metabolic syndrome was not reported in that study ${ }^{(29)}$, probably because the NCEP definition of metabolic syndrome was not available at that time. We believe that the relationship between all anthropometric indices and cardiometabolic risk factors must be analysed in 
further detail in Turkish adults. Compared with North American or European populations, Turks have low levels of total cholesterol (TC) and HDL-C and the relative role of metabolic syndrome and atherogenic dyslipidaemia is more pronounced ${ }^{(30,31)}$. The leading independent predictors of CVD morbidity and mortality are related to the metabolic syndrome, which is responsible for approximately half of the cases of CHD in Turks, making them an ideal population in which to study cardiometabolic risk ${ }^{(30)}$. Therefore, we aimed to investigate whether BMI, WC, WHpR, WHtR or HC is the best anthropometric index to predict cardiometabolic risk factors in Turkish adults.

\section{Methods}

\section{Study population}

The present study is based on the year 2003 follow-up of the Turkish Heart Study, a cross-sectional epidemiological survey of CVD risk factors in Turkish adults performed periodically since $1995^{(31-33)}$. One thousand seven hundred subjects aged 18 years and over were recruited from neighbourhood groups and with local advertisements. The survey was not nationally representative. Four subjects with missing anthropometric measurements, two below 18 years of age and two pregnant women were excluded from the study, leaving 1692 participants for data analysis. The study procedures were approved by the Institutional Review Board and permission to conduct the study was granted by the Ministry of Health, Republic of Turkey. All subjects signed written informed consent. The study was conducted in accordance with the Helsinki Declaration ${ }^{(34)}$.

\section{Data collection}

Information about lifestyle habits, education, physical activity, monthly family income and past medical history was obtained through face-to-face physician interview. BMI was calculated as weight in kilograms divided by the square of height in metres. Height was measured to within $0.5 \mathrm{~cm}$ with a measuring stick, weight to within $0 \cdot 1 \mathrm{~kg}$ with a digital scale, waist and hip circumferences to the nearest $0.5 \mathrm{~cm}$ with a non-elastic measuring tape. WC was measured at the midpoint between the last rib and the superior iliac crest during mild expiration. HC was measured at the level of the greater trochanter. All measurements were taken with shoes removed and with participants wearing light clothing. Blood pressure was measured on the right arm with an automated sphygmomanometer (automatic blood pressure monitor with IntelliSense ${ }^{\circledR}$; Omron, Bannockburn, IL, USA) after the subject had rested for $15 \mathrm{~min}$ in the sitting position. The mean of two recordings, $5 \mathrm{~min}$ apart, was used.

\section{Laboratory metbods}

A blood sample was obtained after a $10 \mathrm{~h}$ fast. Plasma glucose was measured with the glucose oxidase method.
A multichannel analyser (Hitachi, Tokyo, Japan) was used for colorimetric enzymatic determinations of cholesterol (CHOD-PAP), TAG (GPO-PAP) and glucose. For participants with TAG levels $<500 \mathrm{mg} / \mathrm{dl}$, LDL-C was calculated by the Friedewald formula ${ }^{(35)}$. A homogeneous assay for measuring HDL-C levels was used. Kits from BoehringerMannheim (Mannheim, Germany) were used for lipid and glucose analyses. Fasting insulin levels were measured with electrochemiluminescence immunoassay (Roche Elecsys 2010; Roche Diagnostics, Indianapolis, IN, USA). Insulin resistance was estimated with the homeostasis model assessment insulin resistance index (HOMA-IR), calculated from the equation ${ }^{(36)}$ :

$$
\begin{aligned}
\text { HOMA-IR }= & {[\text { fasting serum insulin }(\mu \mathrm{U} / \mathrm{ml})} \\
& \times \text { fasting plasma glucose }(\mathrm{mmol} / \mathrm{l})] / 22 \cdot 5 .
\end{aligned}
$$

Biochemical analyses were performed at the American Hospital Clinical Laboratory in Istanbul, a reference laboratory certified by the Centers for Disease Control and Prevention (Atlanta, GA, USA) ${ }^{(31,32)}$.

\section{Definitions of cardiovascular risk factors}

Components of the metabolic syndrome were defined according to the modified NCEP Adult Treatment Panel III criteria $^{(2,37)}$. The metabolic syndrome score (MSS) was calculated as the sum of the following positive components, excluding WC: (i) systolic blood pressure (SBP) $\geq 130 \mathrm{mmHg}$ or diastolic blood pressure (DBP) $\geq 85 \mathrm{mmHg}$; (ii) serum $\mathrm{TAG} \geq 150 \mathrm{mg} / \mathrm{dl} \quad(1.7 \mathrm{mmol} / \mathrm{l})$; (iii) HDL-C $<50 \mathrm{mg} / \mathrm{dl}(1.29 \mathrm{mmol} / \mathrm{l})$ for women and $<40 \mathrm{mg} / \mathrm{dl}$ $(1.0 \mathrm{mmol} / \mathrm{l})$ for men; and (iv) fasting plasma glucose $\geq 100 \mathrm{mg} / \mathrm{dl}(5.6 \mathrm{mmol} / \mathrm{l})$. Subjects on drug therapy for hypertension, hyperglycaemia or hypertriacylglycerolaemia and low HDL-C levels were also assigned to positive components $^{(37)}$. As WC is one of the independent variables in correlation analyses, its exclusion was considered appropriate in calculating the MSS. Subjects could have MSS ranging from 0 to 4 . MSS was an ordinal variable. Absolute 10-year risk of CHD was calculated from Framingham risk tables ${ }^{(2)}$. The association of each anthropometric index with Framingham risk score was calculated after excluding subjects with a history of CHD ( $n$ 111) and diabetes ( $n$ 103), subjects on lipid-lowering medications $(n 40)$ and subjects younger than 30 years $(n$ 190) and older than 74 years ( $n$ 20), leaving 1228 subjects for this particular correlation analysis. The Framingham risk score has been shown to be inaccurate in the afore-mentioned conditions ${ }^{(38,39)}$. Subjects could have a Framingham risk score from 1 to 30. Framingham risk score was an ordinal variable ${ }^{(2)}$.

Hypertension was defined as concurrent use of antihypertensive agents or SBP $\geq 140 \mathrm{mmHg}$ or $\mathrm{DBP} \geq 90$ $\mathrm{mmHg}^{(40)}$. Hypercholesterolaemia was defined as serum TC $\geq 240 \mathrm{mg} / \mathrm{dl}$, low HDL-C as $<40 \mathrm{mg} / \mathrm{dl}$, high LDL-C as $\geq 160 \mathrm{mg} / \mathrm{dl}$ and hypertriacylglycerolaemia as serum $\mathrm{TAG} \geq 200 \mathrm{mg} / \mathrm{dl}$. The presence of any of the above lipid 
abnormalities defined dyslipidaemia, consistent with the NCEP Adult Treatment Panel III guidelines ${ }^{(2)}$. Diabetes mellitus was diagnosed either from concurrent use of antidiabetic medications or if fasting plasma glucose was $\geq 126 \mathrm{mg} / \mathrm{dl}^{(41)}$. Subjects who had two or more metabolic syndrome components, excluding WC, were classified as 'MSS $\geq 2$ ', a categorical variable that was evaluated as an outcome. A prospective study revealed that persons meeting any two criteria were significantly at higher risk than were those meeting no criteria $^{(42)}$.

\section{Statistical analyses}

Data are summarized by means and standard deviations for normally distributed continuous variables. Continuous variables with positively skewed distributions are presented as geometric means and 95\% confidence intervals, and their logarithmic transformations were employed in correlation analyses. Categorical variables are presented as percentages and 95\% confidence limits and compared with a $\chi^{2}$ test. All statistical analyses were performed for both men and women combined, and separately. Age and sex control were employed when performing correlation analyses for the whole sample ${ }^{(43)}$. Only age control was employed when calculating correlation coefficients for men or women. All anthropometric measurements were continuous variables. Partial correlation coefficients were estimated among BMI, WC, WHpR, WHtR and HC, after controlling for age and sex for the whole sample and age only for each gender. Spearman's rank correlation coefficient was used in correlation analyses between continuous and ordinal variables. Spearman's rank correlation coefficient was calculated between each anthropometric index (continuous variables) and the two composite cardiometabolic risk indicators, MSS and Framingham risk score (ordinal variables). Partial correlation coefficients were calculated between each anthropometric index and SBP, TC, HDL-C, LDL-C, log TAG, glucose and log HOMA-IR, after controlling for age and sex for the whole sample and age only for each gender. Correlation coefficients from 0 to $0 \cdot 25$ (or 0 to $-0 \cdot 25$ ) were regarded as indicating little or no relationship; those from $0 \cdot 25$ to 0.50 (or $-0 \cdot 25$ to $-0 \cdot 50$ ) a fair degree of relationship; those from 0.50 to 0.75 (or -0.50 to -0.75$)$ a moderate to good relationship; and those greater than 0.75 (or -0.75 ) a very good to excellent relationship $^{(44)}$. Statistical significance was accepted if $P<0 \cdot 01$ for correlation analyses and if $P<0.05$ for other analyses.

The receiver-operating characteristic (ROC) calculates the ability of a continuous variable (i.e. WC) to discriminate between the presence and absence of a categorical variable (i.e. metabolic syndrome). As the NCEP definition of the metabolic syndrome already includes elevated WC as a component, we thought it appropriate to exclude WC and derive a new variable called 'metabolic syndrome score' (MSS) by summing other components. MSS (an ordinal variable) was converted to a categorical variable in ROC analysis. If MSS was $\geq 2$, the state variable was positive; if MSS was $<2$, the state variable was negative. The reader should pay attention to this particular aspect: MSS was an ordinal variable in correlation analyses but MSS $\geq 2$ was a categorical variable in ROC analyses. ROC curves were constructed to measure the degree of discrimination of the anthropometric indices for hypertension, dyslipidaemia, diabetes and $\mathrm{MSS} \geq 2$, using non-parametric methods. The areas under the ROC curves (AUC) were calculated for each anthropometric index. An AUC of $1 \cdot 0$ indicates perfect discrimination between the absence and presence of the condition tested, whereas an AUC of 0.5 indicates no discriminative capability. First, the AUC of each anthropometric index was compared with an AUC value of 0.5 , the area under the line of no discrimination. Then differences between the AUC of each anthropometric index for each cardiovascular risk factor were compared using the method of DeLong et al. ${ }^{(45)}$.

Computations were done using the Statistical Package for the Social Sciences statistical software program version 15.0 (SPSS Inc., Chicago, IL, USA) for correlation analyses and the Statistical Analysis Systems statistical software package version 9.1 (SAS Institute Inc., Cary, NC, USA) for ROC analyses.

\section{Results}

There were 1692 participants, 571 men (34\%) and 1121 women (66\%), in the present study; their general characteristics are given in Table 1 . Approximately two-thirds of the subjects ( $n$ 1104, 65\%) were from Istanbul, an urban area, and the remainder ( $n$ 588, 35\%) were from rural areas of Kayseri. Seven per cent ( $n$ 111) of the subjects had a history of self-reported CVD. Sixtythree subjects (4\%) were taking lipid-lowering medications, $271(16 \%)$ were taking antihypertensive agents and 64 (4\%) were taking oral antidiabetics. The frequency of CVD risk factors is presented in Table 1 . The distribution of lipid abnormalities was as follows: $8 \%$ ( $n$ 137) had hypercholesterolaemia, 40\% ( $n$ 672) low HDL-C, 9\% ( $n$ 144) high LDL-C and 16\% ( $n$ 262) elevated TAG. As a subject could have more than one lipid abnormality, the sum of lipid abnormalities exceeded the number of subjects with dyslipidaemia. Seven per cent ( $n 75)$ of women reported participation in physical exercise for $>4 \mathrm{~h} /$ week, $10 \%$ ( $n$ 114) reported $1-4 \mathrm{~h} /$ week, 6\% ( $n$ 71) reported $<1 \mathrm{~h} /$ week and $77 \%$ ( $n$ 861) reported no exercise. Among men, $11 \%$ ( $n$ 61) reported physical exercise for $>4 \mathrm{~h} /$ week, $15 \%$ ( $n 87$ ) reported $1-4 \mathrm{~h} /$ week, $10 \%$ ( $n$ 57) $<1 \mathrm{~h} /$ week and 64\% ( $n$ 366) reported no exercise. The physical activity level of men was significantly greater than that of women $\left(\chi^{2}=30 \cdot 76\right.$, dof $\left.=3, P<0 \cdot 01\right)$.

Age- and sex-controlled correlations among BMI, WC, WHpR, WHtR and HC are shown in Table 2. Except for the association between $\mathrm{HC}$ and $\mathrm{WHpR}$, all anthropometric 
Table 1 Clinical characteristics of the study sample: Turkish men and women aged 18 years and over, 2003

\begin{tabular}{|c|c|c|c|c|c|c|}
\hline \multirow[b]{2}{*}{ Characteristic } & \multicolumn{2}{|c|}{ All (n 1692) } & \multicolumn{2}{|c|}{ Men $(n 571)$} & \multicolumn{2}{|c|}{ Women (n 1121) } \\
\hline & Mean & SD & Mean & SD & Mean & SD \\
\hline Age (years) & $45 \cdot 4$ & $13 \cdot 1$ & $44 \cdot 8$ & $13 \cdot 0$ & $45 \cdot 7$ & $13 \cdot 1$ \\
\hline Weight (kg) & $76 \cdot 3$ & $13 \cdot 9$ & $82 \cdot 6$ & $12 \cdot 8$ & $73 \cdot 1$ & $13 \cdot 4$ \\
\hline Height (cm) & $160 \cdot 7$ & $9 \cdot 9$ & $170 \cdot 7$ & $7 \cdot 3$ & $155 \cdot 7$ & $6 \cdot 7$ \\
\hline BMI $\left(\mathrm{kg} / \mathrm{m}^{2}\right)$ & $29 \cdot 6$ & $5 \cdot 0$ & $28 \cdot 3$ & $3 \cdot 7$ & $30 \cdot 2$ & $5 \cdot 4$ \\
\hline WC $(\mathrm{cm})$ & $95 \cdot 1$ & $12 \cdot 3$ & $99 \cdot 6$ & $10 \cdot 3$ & $92 \cdot 7$ & $12 \cdot 6$ \\
\hline $\mathrm{HC}(\mathrm{cm})$ & $110 \cdot 2$ & $10 \cdot 0$ & $107 \cdot 8$ & $7 \cdot 5$ & $111 \cdot 5$ & $10 \cdot 8$ \\
\hline WHpR & 0.86 & 0.08 & 0.92 & 0.06 & $0 \cdot 83$ & 0.08 \\
\hline WHtR & 0.59 & 0.08 & 0.58 & 0.06 & 0.60 & 0.09 \\
\hline Hypertension (\%)† & $45 \cdot 6$ & $2 \cdot 3$ & $44 \cdot 5$ & $4 \cdot 0$ & $46 \cdot 2$ & $2 \cdot 9$ \\
\hline Diabetes $(\%) \dagger$ & $7 \cdot 0$ & $1 \cdot 2$ & $7 \cdot 0$ & $2 \cdot 0$ & $7 \cdot 0$ & $1 \cdot 4$ \\
\hline Dyslipidaemia (\%)† & $50 \cdot 9$ & $2 \cdot 3$ & $67 \cdot 1$ & $3 \cdot 8$ & $42 \cdot 6$ & $2 \cdot 8$ \\
\hline Metabolic syndrome (\%)† & $45 \cdot 8$ & $2 \cdot 3$ & $43 \cdot 8$ & $4 \cdot 0$ & $46 \cdot 8$ & $2 \cdot 9$ \\
\hline MSS $\geq 2(\%) \dagger$ & $55 \cdot 0$ & $2 \cdot 3$ & $58 \cdot 1$ & $4 \cdot 0$ & $53 \cdot 3$ & $2 \cdot 9$ \\
\hline SBP $(\mathrm{mmHg})$ & $134 \cdot 7$ & $24 \cdot 2$ & $133 \cdot 4$ & $19 \cdot 9$ & $135 \cdot 4$ & $26 \cdot 1$ \\
\hline DBP $(\mathrm{mmHg})$ & $85 \cdot 8$ & $12 \cdot 9$ & $85 \cdot 3$ & $11 \cdot 8$ & $86 \cdot 0$ & $13 \cdot 4$ \\
\hline Glucose (mmol/l) & $5 \cdot 4$ & $1 \cdot 7$ & $5 \cdot 5$ & $1 \cdot 7$ & $5 \cdot 3$ & $1 \cdot 7$ \\
\hline HOMA-IR $\ddagger$ & $1 \cdot 68$ & $1 \cdot 63,1 \cdot 74$ & $1 \cdot 76$ & $1 \cdot 66,1 \cdot 86$ & $1 \cdot 64$ & $1.58,1.71$ \\
\hline TC $(\mathrm{mmol} / \mathrm{l})$ & $4 \cdot 77$ & 1.03 & $4 \cdot 71$ & 0.93 & $4 \cdot 81$ & $1 \cdot 08$ \\
\hline HDL-C (mmol/l) & $1 \cdot 14$ & 0.31 & $1 \cdot 00$ & 0.25 & $1 \cdot 22$ & $0 \cdot 31$ \\
\hline LDL-C (mmol/l) & $2 \cdot 93$ & 0.88 & $2 \cdot 91$ & $0 \cdot 81$ & $2 \cdot 95$ & 0.92 \\
\hline TAG $(\mathrm{mmol} / \mathrm{l}) \ddagger$ & $1 \cdot 33$ & $1 \cdot 29,1 \cdot 36$ & $1 \cdot 52$ & $1 \cdot 46,1 \cdot 59$ & $1 \cdot 24$ & $1 \cdot 20,1 \cdot 27$ \\
\hline
\end{tabular}

WC, waist circumference, $\mathrm{HC}$, hip circumference, WHpR, waist:hip ratio; WHtR, waist:height ratio; Metabolic syndrome, subjects with three or more of National Cholesterol Education Program (NCEP)-defined metabolic syndrome components; MSS $\geq 2$, subjects with two or more NCEP-defined metabolic syndrome components excluding WC; SBP, systolic blood pressure; DBP, diastolic blood pressure; HOMA-IR, homeostasis model assessment of insulin resistance; TC, total cholesterol, HDL-C, HDL cholesterol, LDL-C, LDL cholesterol.

Data are presented as arithmetic mean and standard deviation, or tpercentage and $95 \%$ confidence limit, or łgeometric mean and $95 \%$ confidence interval.

Table 2 Correlation coefficients between anthropometric indices in Turkish adults: men and women aged 18 years and over, 2003

\begin{tabular}{|c|c|c|c|c|}
\hline & WC & WHpR & WHtR & $\mathrm{HC}$ \\
\hline \multicolumn{5}{|c|}{ All subjectst } \\
\hline BMI & $0 \cdot 81^{*}$ & $0 \cdot 29^{*}$ & $0.83^{*}$ & $0 \cdot 86^{*}$ \\
\hline WC & & $0.69^{*}$ & $0.94^{*}$ & $0 \cdot 74^{*}$ \\
\hline WHpR & & & $0 \cdot 69^{*}$ & 0.04 \\
\hline $\mathrm{WHtR}$ & & & & $0 \cdot 68^{*}$ \\
\hline \multicolumn{5}{|l|}{ Men‡ } \\
\hline BMI & $0.81^{*}$ & $0.46^{*}$ & $0.84^{*}$ & $0 \cdot 80^{*}$ \\
\hline WC & & $0 \cdot 77^{\star}$ & $0.93^{*}$ & $0 \cdot 78^{*}$ \\
\hline WHpR & & & $0 \cdot 78^{\star}$ & $0 \cdot 21^{*}$ \\
\hline $\mathrm{WHtR}$ & & & & $0 \cdot 66^{*}$ \\
\hline \multicolumn{5}{|l|}{ Women§̧ } \\
\hline BMI & $0.81^{*}$ & $0.23^{*}$ & $0.82^{*}$ & $0 \cdot 88^{*}$ \\
\hline WC & & $0.66^{\star}$ & $0.95^{\star}$ & $0.73^{*}$ \\
\hline WHpR & & & $0.66^{\star}$ & -0.02 \\
\hline $\mathrm{WHtR}$ & & & & $0.67^{\star}$ \\
\hline
\end{tabular}

WC, waist circumference; WHpR, waist:hip ratio; WHtR, waist:height ratio; $\mathrm{HC}$, hip circumference.

*Significant correlation: $P<0.01$.

t $n$ 1692, correlation analyses controlled for age and sex.

$\ddagger n 571$, correlation analyses controlled for age.

$\S n 1121$, correlation analyses controlled for age.

indices were significantly correlated with each other. The correlation between BMI and WC, WHtC or HC and the correlation between WC and WHtR were very good to excellent. The other correlations were lesser in magnitude.

Spearman's rank correlation coefficient between MSS and BMI, WC, WHpR, WHtR and HC was $0 \cdot 40,0 \cdot 44,0 \cdot 33$, $0 \cdot 46$ and $0 \cdot 28$, respectively $(P<0 \cdot 001$ for all), for the whole sample. In men, the corresponding Spearman rank correlation coefficients were $0 \cdot 36,0 \cdot 36,0 \cdot 35,0 \cdot 38$ and
$0 \cdot 22$, respectively $(P<0 \cdot 001$ for all); in women, they were $0.45,0 \cdot 49,0.38,0.51$ and 0.34 , respectively $(P<0 \cdot 001$ for all). In the subset of subjects between the ages of 30 and 74 years who did not have CVD, diabetes mellitus and were not taking lipid-lowering agents ( $n$ 1228), Spearman's rank correlation coefficient between Framingham risk score (10-year absolute risk of CVD) and anthropometric index was $0 \cdot 16$ for BMI, $0 \cdot 17$ for WC, 0.14 for WHpR, 0.29 for WHtR $(P<0.001$ for all $)$ and $0 \cdot 10$ for $\mathrm{HC}(P=0 \cdot 001)$. In the same subset of men ( $n$ 420), Spearman's rank correlation coefficient between Framingham risk score and anthropometric index was 0.05 for BMI $(P=0 \cdot 36), 0 \cdot 06$ for WC $(P=0 \cdot 26), 0 \cdot 15$ for WHpR $(P=0 \cdot 003), 0 \cdot 15$ for WHtR $(P=0.002)$ and -0.07 for HC $(P=0 \cdot 14)$. In the same subset of women ( $n 808)$, the corresponding Spearman rank correlation coefficients were $0 \cdot 18,0 \cdot 27,0 \cdot 28,0 \cdot 33$ and $0 \cdot 14$, respectively $(P<0 \cdot 001$ for all $)$.

Partial correlation coefficients between each anthropometric index and major CVD risk factors or HOMA-IR were assessed after controlling for age and sex (Table 3). In the whole sample, the correlation between $\mathrm{HC}$ and TC or LDL-C was statistically significant but represented little or no relationship in magnitude. The correlation coefficients with other anthropometric measurements were not statistically significant for TC and LDL-C. The correlation coefficient between HC and glucose was also not significant. All other correlations were statistically significant, but the relationships were fair or lower. For the whole sample, the correlation coefficients of BMI, WC and WHtR 
were higher than the correlation coefficients of WHpR and $\mathrm{HC}$ for most of the CVD risk factors. In men, no anthropometric index was clearly superior. In women,

Table 3 Correlation coefficients between anthropometric indices and cardiovascular risk factors in Turkish adults: men and women aged 18 years and over, 2003

\begin{tabular}{|c|c|c|c|c|c|}
\hline & BMI & WC & WHpR & WHtR & $\mathrm{HC}$ \\
\hline \multicolumn{6}{|l|}{ All subjects† } \\
\hline SBP & $0 \cdot 28^{*}$ & $0 \cdot 28^{*}$ & $0 \cdot 15^{\star}$ & $0 \cdot 29^{*}$ & $0 \cdot 25^{\star}$ \\
\hline $\mathrm{TC}$ & 0.05 & 0.05 & 0.01 & 0.03 & $0.07^{*}$ \\
\hline HDL-C & $-0 \cdot 24^{*}$ & $-0 \cdot 26^{*}$ & $-0 \cdot 23^{*}$ & $-0 \cdot 27^{*}$ & $-0 \cdot 16^{\star}$ \\
\hline & 0.04 & 0.04 & -0.01 & 0.02 & $0.07^{*}$ \\
\hline Lo & $0.2 \varepsilon$ & 0.2 & & $0.29^{*}$ & $0 \cdot 19^{*}$ \\
\hline & 0.0 & $0 \cdot 0$ & $0 \cdot 0$ & $0.09^{*}$ & 0.04 \\
\hline $\log$ & $0.45^{*}$ & $0.45^{\star}$ & $0 \cdot 28^{*}$ & $0.43^{*}$ & $0 \cdot 37^{*}$ \\
\hline \multicolumn{6}{|l|}{ Men‡ } \\
\hline SBP & $0 \cdot 21^{*}$ & $0 \cdot 20^{*}$ & $0 \cdot 14^{*}$ & $0 \cdot 19^{*}$ & $0 \cdot 17^{\star}$ \\
\hline & $0 \cdot 1$ & $0 \cdot 1$ & $0 \cdot 12^{*}$ & $0 \cdot 11^{*}$ & 0.07 \\
\hline $\mathrm{HD}$ & $-0 \cdot 22^{*}$ & $-0 \cdot 19^{*}$ & $-0 \cdot 18^{\star}$ & $-0 \cdot 21^{*}$ & $-0 \cdot 11^{\star}$ \\
\hline & 0.08 & 0.08 & 0.05 & 0.05 & 0.07 \\
\hline Log & $0 \cdot 26^{*}$ & $0 \cdot 25^{\star}$ & $0.28^{*}$ & $0 \cdot 29^{*}$ & $0 \cdot 12^{*}$ \\
\hline & 0.04 & 0.04 & $0.09^{*}$ & 0.06 & -0.02 \\
\hline Log $\mathrm{H}$ & $0.52^{*}$ & $0.53^{*}$ & $0 \cdot 40^{*}$ & $0.52^{*}$ & $0.43^{*}$ \\
\hline \multicolumn{6}{|l|}{ Womens } \\
\hline SBP & $0 \cdot 28^{*}$ & $0 \cdot 28^{*}$ & $0 \cdot 15^{\star}$ & $0 \cdot 30^{*}$ & $0 \cdot 25^{\star}$ \\
\hline $\mathrm{TC}$ & 0.00 & -0.01 & -0.06 & -0.04 & 0.04 \\
\hline HDL-C & $-0 \cdot 24^{*}$ & $-0 \cdot 29^{*}$ & $-0 \cdot 24^{*}$ & $-0 \cdot 29^{*}$ & $-0 \cdot 17^{\star}$ \\
\hline & 0.01 & 0.00 & -0.04 & -0.02 & 0.05 \\
\hline & $0 \cdot 27^{\star}$ & $0 \cdot 28^{*}$ & & $0.27^{\star}$ & $0 \cdot 20^{*}$ \\
\hline Glu & $0.08^{*}$ & $0.09^{*}$ & $0.08^{*}$ & $0.09^{*}$ & 0.05 \\
\hline Log HOMA-IR & $0 \cdot 43^{*}$ & $0 \cdot 41^{*}$ & $0.23^{*}$ & $0.39^{*}$ & $0.35^{\star}$ \\
\hline
\end{tabular}

WC, waist circumference; WHpR, waist:hip ratio; WHtR, waist:height ratio; $\mathrm{HC}$, hip circumference; SBP, systolic blood pressure; TC, total cholesterol; HDL-C, HDL cholesterol; LDL-C, LDL cholesterol; HOMA-IR, homeostasis model assessment of insulin resistance.

*Significant correlation: $P<0.01$.

t $n$ 1692, correlation analyses controlled for age and sex.

$\ddagger n 571$, correlation analyses controlled for age.

$\S n 1121$, correlation analyses controlled for age. both WC and WHtR had the highest correlations for the studied cardiometabolic risk factors.

As correlation analyses did not provide a clear answer to the question of 'the best anthropometric index for cardiometabolic risk', we analysed the data with ROC curves. Analysis of ROC curves showed that WHtR was the best anthropometric index for discrimination of hypertension, diabetes and metabolic syndrome. For discrimination of dyslipidaemia, WHpR seemed better for the whole sample (Table 4). It should be noted that the area under a ROC curve is a measure of the anthropometric index's ability to discriminate between the presence and absence of the condition tested. BMI, WC, WHpR, WHtR and HC were all significant discriminators of cardiometabolic risk factors, as their AUC values were significantly greater than 0.5 $(P<0 \cdot 01$ for all indices, except some AUC for diabetes and dyslipidaemia in men). The AUC of HC was inferior to others in discriminating the presence or absence of hypertension, diabetes and metabolic syndrome. There were no differences in AUC of BMI and WC for hypertension, diabetes and metabolic syndrome. In men, AUC of WHtR was the largest for hypertension and MSS $\geq 2$ and AUC of WHpR was the largest for diabetes (Table 4). In women, AUC of WHtR was the largest for hypertension and MSS $\geq 2(P<0 \cdot 05)$ and AUC of WHtR, WHpR and WC were larger than others for dyslipidemia and diabetes $(P<0 \cdot 05)$, as seen in Table 4 .

\section{Discussion}

WHtR seemed a better anthropometric index that could predict most cardiometabolic risk factors in the present

Table 4 Area under the receiver-operating characteristic curves (AUC) for anthropometric indices

\begin{tabular}{|c|c|c|c|c|c|c|c|c|c|c|}
\hline & \multicolumn{2}{|c|}{$\mathrm{BMI}$} & \multicolumn{2}{|c|}{ WC } & \multicolumn{2}{|c|}{ WHpR } & \multicolumn{2}{|c|}{ WHtR } & \multicolumn{2}{|c|}{$\mathrm{HC}$} \\
\hline & AUC & $95 \% \mathrm{Cl}$ & AUC & $95 \% \mathrm{Cl}$ & AUC & $95 \% \mathrm{Cl}$ & $A \cup C$ & $95 \% \mathrm{Cl}$ & AUC & $95 \% \mathrm{Cl}$ \\
\hline \multicolumn{11}{|l|}{ All subjectst } \\
\hline Hypertension & $0 \cdot 71^{b, c, d}$ & $0.68,0.73$ & $0.71^{e, f, g}$ & $0.69,0.74$ & $0.63^{h}$ & $0.61,0.66$ & $0 \cdot 75^{\mathrm{j}}$ & $0.73,0.77$ & 0.66 & $0.64,0.69$ \\
\hline Dyslipidaemia & $0.57^{a, b, c, d}$ & $0.55,0.60$ & $0 \cdot 64^{e, f, g}$ & $0.62,0.67$ & $0 \cdot 66^{h, i}$ & $0.64,0.69$ & $0 \cdot 61^{j}$ & $0.58,0.64$ & 0.54 & $0.51,0.56$ \\
\hline Diabetes & $0 \cdot 62^{c, d}$ & $0.57,0.68$ & $0 \cdot 66^{f, g}$ & $0.62,0.71$ & $0.64^{\mathrm{h}}$ & $0.59,0.68$ & $0 \cdot 70^{j}$ & $0.65,0.74$ & 0.57 & $0.52,0.63$ \\
\hline$M S S \geq 2$ & $0 \cdot 71^{\mathrm{c}, \mathrm{d}}$ & $0.69,0.74$ & $0.73^{e, f, g}$ & $0 \cdot 70,0 \cdot 75$ & $0.67^{h}$ & $0.64,0.69$ & $0 \cdot 74^{\mathrm{j}}$ & $0 \cdot 72,0.77$ & 0.65 & $0.63,0.68$ \\
\hline \multicolumn{11}{|l|}{ Men $\ddagger$} \\
\hline Hypertension & $0 \cdot 66^{d}$ & $0.62,0.71$ & $0 \cdot 66^{f, g}$ & $0.61,0.70$ & $0 \cdot 63^{h}$ & $0.59,0.68$ & $0 \cdot 69^{j}$ & $0.64,0.73$ & $0 \cdot 61$ & $0.57,0.66$ \\
\hline Dyslipidaemia & $0 \cdot 61^{d}$ & $0.56,0.66$ & $0 \cdot 60^{g}$ & $0.55,0.65$ & $0 \cdot 61$ & $0.56,0.66$ & $0 \cdot 61$ & $0.56,0.66$ & $0.54 \|$ & $0.49,0.59$ \\
\hline Diabetes & $0.52 \|$ & $0.42,0.62$ & $0.57 \|$ & $0.47,0.66$ & 0.64 & $0.55,0.74$ & $0 \cdot 61$ & $0.52,0.70$ & $0.46 \|$ & $0.36,0.56$ \\
\hline$M S S \geq 2$ & $0.68^{d}$ & $0.64,0.73$ & $0.69^{9}$ & $0.65,0.74$ & $0.68^{i}$ & $0.64,0.73$ & $0 \cdot 70^{j}$ & $0 \cdot 66,0.74$ & 0.61 & $0.57,0.66$ \\
\hline \multicolumn{11}{|l|}{ Women§ } \\
\hline Hypertension & $0 \cdot 73^{\mathrm{a}, \mathrm{b}, \mathrm{c}, \mathrm{d}}$ & $0.70,0.76$ & $0 \cdot 76^{\mathrm{e}, \mathrm{f}, \mathrm{g}}$ & $0.73,0.79$ & $0 \cdot 69^{h}$ & $0.66,0.72$ & $0 \cdot 78^{j}$ & $0.75,0.80$ & 0.69 & $0.66,0.72$ \\
\hline Dyslipidaemia & $0 \cdot 60^{\mathrm{a}, \mathrm{c}, \mathrm{d}}$ & $0.57,0.63$ & $0 \cdot 63^{g}$ & $0.60,0.66$ & $0 \cdot 62^{i}$ & $0.59,0.65$ & $0 \cdot 63^{j}$ & $0.60,0.66$ & 0.57 & $0.54,0.60$ \\
\hline Diabetes & $0 \cdot 67^{\mathrm{a}, \mathrm{c}, \mathrm{d}}$ & $0.61,0.73$ & $0 \cdot 72^{\mathrm{g}}$ & $0.67,0.77$ & 0.69 & $0.64,0.74$ & $0 \cdot 73^{j}$ & $0.68,0.78$ & 0.63 & $0.56,0.69$ \\
\hline$M S S \geq 2$ & $0 \cdot 74^{\mathrm{b}, \mathrm{c}, \mathrm{d}}$ & $0.71,0.77$ & $0.75^{e, f, g}$ & $0.72,0.78$ & $0 \cdot 70^{\mathrm{h}}$ & $0.66,0.73$ & $0 \cdot 76^{j}$ & $0.74,0.79$ & 0.68 & $0.65,0.71$ \\
\hline
\end{tabular}

WC, waist circumference; WHpR, waist:hip ratio; WHtR, waist:height ratio; HC, hip circumference; MSS $\geq 2$, subjects with two or more National Cholesterol Education Program-defined metabolic syndrome components, excluding WC.

$\mathrm{a}, \mathrm{b}, \mathrm{c}, \mathrm{d}, \mathrm{e}, \mathrm{f}, \mathrm{g}, \mathrm{h}, \mathrm{i}, \mathrm{j}$ Within a row, $P<0.05$ for the following comparisons of AUC: ${ }^{\mathrm{a}} \mathrm{BMI} v$. WC, ${ }^{\mathrm{b}} \mathrm{BMI} v$. WHpR, ${ }^{\mathrm{c}} \mathrm{BMI} v$. WHtR, ${ }^{\mathrm{d}} \mathrm{BMI} v$. HC, ${ }^{\mathrm{e}} \mathrm{WC} v$. WHpR, ${ }^{\mathrm{f}} \mathrm{WC} v$. WHtR, ${ }^{g}$ WC $v . \mathrm{HC},{ }^{\mathrm{h}} \mathrm{WH}$ pR $v$. WHtR, ${ }^{\mathrm{i}} \mathrm{WHpR} v . \mathrm{HC},{ }^{\mathrm{j}} \mathrm{WH} \mathrm{HR} v . \mathrm{HC}$.

tn 1692 .

$\ddagger n 571$.

$\S n 1121$.

$\| P>0.05$ compared with 0.50 , the value that indicates the area under the line of no discrimination; therefore comparison with other anthropometric indices was not performed. 
study. Although there was little difference among BMI, WC and WHtR in relation to CVD risk factors in correlation analyses, evaluation of AUC in ROC curve analyses indicated WHtR as a better predictor of hypertension, diabetes and metabolic syndrome. The differences among anthropometric indices were small and, in most instances, the confidence interval of one index substantially crossed the confidence interval of the other indices. Studies using computed tomography and MRI have revealed that central obesity indicators, especially visceral abdominal adipose tissue mass, are major contributors to cardiometabolic risk ${ }^{(46-48)}$. Although studies that relate anthropometric indices with body composition and fat distribution reveal consistent results, the same is not true for comparative studies relating anthropometrics with cardiometabolic risk factors. Comparative prospective studies vary in their conclusions as to whether BMI, WC or WHpR is superior in predicting all-cause mortality, CVD mortality and morbidity ${ }^{(3-10)}$. Prospective studies with WHtR and HC are scarce ${ }^{(15,49)}$.

Our results show that the effort to pinpoint to the best anthropometric index is hampered by the definition of the outcome. We found that the best anthropometric index varies whether one tries to predict hypertension, dyslipidaemia, diabetes or metabolic syndrome. The best anthropometric measure also varies according to race, ethnicity, gender and age group ${ }^{(3-22)}$. For example, in the Tehran Glucose and Lipid Study, analysis of crosssectional data showed that WHpR was the best screening measure for CVD risk factors in men, whereas WC was the best in women ${ }^{(23,24)}$. In the prospective phase of the Tehran Glucose and Lipid Study, both BMI and WHpR were better predictors of incident diabetes in subjects younger than 60 years of age, whereas WC was better in subjects older than 60 years ${ }^{(26)}$

As overweight and obese patients with established CHD have lower risk of overall mortality and CVD mortality than normal-weight patients ${ }^{(50,51)}$, it has been suggested that BMI can be left aside as a clinical and epidemiological measure of CVD risk for both primary and secondary prevention ${ }^{(52)}$. The present study shows no difference in BMI, a surrogate measure of general obesity, and WC, a surrogate of central obesity, in relation to cardiovascular risk factors. The correlations between MSS or Framingham risk score and anthropometrics were fair for all indices and were similar in degree for BMI, WC and WHtR in our study. WHpR seemed a better index for discrimination of dyslipidaemia for the whole sample. The subjects with dyslipidaemia in the present study were different from other populations, as the proportion of subjects with low HDL-C without elevated TAG was high. Low HDL-C is thought to have a genetic basis in the Turkish population and studies are underway to attempt to resolve the issue $^{(53)}$.

Incorporating either $\mathrm{HC}$ or height into $\mathrm{WC}$ may provide more information on cardiometabolic risk than WC alone.
Studies from Europe and North America have shown that $\mathrm{HC}$ is inversely associated with diabetes and dyslipidae$\mathrm{mia}^{(49,54)}$. HC has been shown to be positively associated with lower body fat and gluteal muscle mass and negatively associated with visceral abdominal adipose tissue, after controlling for age and $\mathrm{WC}^{(55)}$, and is proposed as a screening measure that confers protection from $\mathrm{CVD}^{(15)}$. WC and HC may give information on both intra-abdominal and peripheral fat mass, factors that have opposite effects on cardiometabolic risk. In our sample of Turkish adults who had a high frequency of metabolic syndrome, both HC and WHpR were significantly correlated with various cardiometabolic risk factors, but in a smaller degree than other anthropometric indices. Our study shows that the use of height rather than hip adjustment for WC better indicates the clustering of cardiometabolic risk factors. The universal use of WC may cause overestimation of cardiometabolic risk in tall persons and underestimation of risk in short persons ${ }^{(14)}$. It has been shown that height has an inverse association with $\mathrm{CVD}^{(56,57)}$. As seen in Table 1, Turkish men and women are shorter than their counterparts elsewhere in Europe. In contrast to other studies from Turkey ${ }^{(28,29)}$, we believe it will be appropriate to use WHtR rather than WHpR to assess cardiometabolic risk in Turkish adults. Future prospective studies should investigate the best cut-off points for WHtR.

\section{Limitations of the study}

Associations of anthropometric measurements with diabetes, hypertension, dyslipidaemia and CVD are documented by several studies and the predictive ability of different indices varies among populations ${ }^{(10-19)}$. It is of interest from a public health perspective to identify the best predictor for a specific population, and this goal can only be accomplished by long-term prospective studies. A major limitation of the present study is its cross-sectional design. Another limitation is that a non-representative sample of the Turkish population was evaluated and this could introduce a selection bias. Compared with persons sampled in the Turkish Ministry of Interior Affairs, Office of Population and Citizenship 2003 household survey ${ }^{(58)}$, we sampled approximately $20 \%$ fewer subjects in the age group of 20-29 years and $10 \%$ more subjects in the age groups of both 40-49 and 50-59 years. The health-care system in Turkey is not free. As laboratory tests, a thorough physical examination and post-study dietary and medical advice were offered free to participants, subjects with the studied conditions could have self-selected themselves to participate. These limitations should be considered when generalizing our results to the wider Turkish population. On the other hand, a representative study $^{(59)}$ from Turkey reported the mean BMI of Turkish women as $30.0 \mathrm{~kg} / \mathrm{m}^{2}$ and of men as $28.5 \mathrm{~kg} / \mathrm{m}^{2}$, similar to our results (Table 1). Another representative study reported the prevalence of obesity as $35 \%$ overall, $21 \%$ in 
men and $41 \%$ in women ${ }^{(60)}$. Four per cent of our sample was on glucose-lowering medications. Some subjects may have been on PPAR- $\gamma$ agonists, a new class of antidiabetics which may alter body fat distribution. However we suspect that the number of such subjects is small, because PPAR- $\gamma$ agonists are expensive and were introduced on the Turkish market only one year before our study.

In conclusion, we found that WHtR was the best anthropometric index for predicting most cardiometabolic risk factors. BMI and WC ranked second for their predictive capability of cardiometabolic risk, followed by WHpR. HC was the worst predictor. All anthropometric measures of obesity were significantly associated with cardiovascular and metabolic risk factors.

\section{Acknowledgements}

Conflict of interest: The authors declare that they have no conflict of interest.

Funding support: All authors are funded by their institutions. The cost of the laboratory work was supported by the Gladstone Institute of Cardiovascular Disease.

Authors' contributions: A.S.C. contributed to data acquisition and evaluation, and wrote the manuscript. T.P.B. contributed to data acquisition and evaluation. M.G. contributed to statistical analysis.

\section{References}

1. World Health Organization (1997) Obesity: Preventing and Managing the Global Epidemic. Report of a WHO Consultation on Obesity, 3-5 June 1997, Geneva, WHO/ NUT/NCD/98.1. Geneva: WHO.

2. Expert Panel on Detection, Evaluation, and Treatment of High Blood Cholesterol in Adults (2001) Executive Summary of The Third Report of The National Cholesterol Education Program (NCEP) Expert Panel on Detection, Evaluation, And Treatment of High Blood Cholesterol In Adults (Adult Treatment Panel III). JAMA 285, 2486-2497.

3. Simpson JA, MacInnis RJ, Peeters A, Hopper JL, Giles GG \& English DR (2007) A comparison of adiposity measures as predictors of all-cause mortality: the Melbourne Collaborative Cohort Study. Obesity (Silver Spring) 15, 994-1003.

4. Batty GD, Kivimaki M, Smith GD, Marmot MG \& Shipley MJ (2007) Obesity and overweight in relation to mortality in men with and without type 2 diabetes/impaired glucose tolerance: the original Whitehall Study. Diabetes Care 30, 2388-2391.

5. Bigaard J, Tjonneland A, Thomsen BL, Overvad K, Heitmann BL \& Sorensen TI (2003) Waist circumference, BMI, smoking, and mortality in middle-aged men and women. Obes Res 11, 895-903.

6. Welborn TA, Dhaliwal SS \& Bennett SA (2003) Waist-hip ratio is the dominant risk factor predicting cardiovascular death in Australia. Med J Aust 179, 580-585.

7. Visscher TL, Seidell JC, Molarius A, van der Kuip D, Hofman A \& Witteman JC (2001) A comparison of body mass index, waist-hip ratio and waist circumference as predictors of all-cause mortality among the elderly: the Rotterdam study. Int J Obes Relat Metab Disord 25, $1730-1735$.
8. Yusuf S, Hawken S, Ounpuu S et al.; INTERHEART Study Investigators (2005) Obesity and the risk of myocardial infarction in 27,000 participants from 52 countries: a case-control study. Lancet 366, 1640-1649.

9. Katzmarzyk PT \& Craig CL (2006) Independent effects of waist circumference and physical activity on all-cause mortality in Canadian women. Appl Physiol Nutr Metab 31, 271-276.

10. Folsom AR, Kushi LH, Anderson KE, Mink PJ, Olson JE, Hong CP, Sellers TA, Lazovich D \& Prineas RJ (2000) Associations of general and abdominal obesity with multiple health outcomes in older women: the Iowa Women's Health Study. Arch Intern Med 160, 2117-2128.

11. Hsieh SD \& Muto T (2005) The superiority of waist-toheight ratio as an anthropometric index to evaluate clustering of coronary risk factors among non-obese men and women. Prev Med 40, 216-220.

12. Schneider HJ, Glaesmer H, Klotsche J, Bohler S, Lehnert H, Zeiher AM, Marz W, Pittrow D, Stalla GK \& Wittchen HU (2007) Accuracy of anthropometric indicators of obesity to predict cardiovascular risk. J Clin Endocrinol Metab 92, 589-594.

13. Fuchs FD, Gus M, Moreira LB, Moraes RS, Wiehe M, Pereira GM \& Fuchs SC (2005) Anthropometric indices and the incidence of hypertension: a comparative analysis. Obes Res 13, 1515-1517.

14. Hsieh SD \& Muto T (2006) Metabolic syndrome in Japanese men and women with special reference to the anthropometric criteria for the assessment of obesity: proposal to use the waist-to-height ratio. Prev Med 42, 135-139.

15. Lissner L, Bjorkelund C, Heitmann BL, Seidell JC \& Bengtsson C (2001) Larger hip circumference independently predicts health and longevity in a Swedish female cohort. Obes Res 9, 644-646.

16. Lorenzo C, Serrano-Rios M, Martinez-Larrad MT, GonzalezVillalpando C, Williams K, Gabriel R, Stern MP \& Haffner SM (2007) Which obesity index best explains prevalence differences in type 2 diabetes mellitus? Obesity (Silver Spring) 15, 1294-1301.

17. Dalton M, Cameron AJ, Zimmet PZ, Shaw JE, Jolley D, Dunstan DW \& Welborn TA (2003) Waist circumference, waist-hip ratio and body mass index and their correlation with cardiovascular disease risk factors in Australian adults. J Intern Med 254, 555-563.

18. Aekplakorn W, Kosulwat V \& Suriyawongpaisal P (2006) Obesity indices and cardiovascular risk factors in Thai adults. Int J Obes (Lond) 30, 1782-1790.

19. Lofgren I, Herron K, Zern T, West K, Patalay M, Shachter NS, Koo SI \& Fernandez ML (2004) Waist circumference is a better predictor than body mass index of coronary heart disease risk in overweight premenopausal women. $J$ Nutr 134, 1071-1076.

20. Nakamura Y, Turin TC, Kita Y, Tamaki S, Tsujita Y, Kadowaki T, Murakami Y, Okamura T \& Ueshima H (2007) Associations of obesity measures with metabolic risk factors in a community-based population in Japan. Circ J 71, 776-781.

21. Chul Sung K, Ryu S \& Reaven GM (2007) Relationship between obesity and several cardiovascular disease risk factors in apparently healthy Korean individuals: comparison of body mass index and waist circumference. Metabolism 56, 297-303.

22. Wang Z, Rowley K, Piers L \& O'Dea K (2007) Anthropometric indices and their relationship with diabetes, hypertension and dyslipidemia in Australian Aboriginal people and Torres Strait Islanders. Eur J Cardiovasc Prev Rehabil 14, 172-178.

23. Esmaillzadeh A, Mirmiran P \& Azizi F (2004) Waist-to-hip ratio is a better screening measure for cardiovascular risk factors than other anthropometric indicators in Tehranian adult men. Int J Obes Relat Metab Disord 28, 1325-1332. 
24. Esmaillzadeh A, Mirmiran P \& Azizi F (2006) Comparative evaluation of anthropometric measures to predict cardiovascular risk factors in Tehranian adult women. Public Health Nutr 9, 61-69.

25. Hadaegh F, Zabetian A, Harati H \& Azizi F (2006) Waist/ height ratio as a better predictor of type 2 diabetes compared to body mass index in Tehranian adult men - a 3.6-year prospective study. Exp Clin Endocrinol Diabetes 114, 310-315.

26. Hadaegh F, Zabetian A, Harati H \& Azizi F (2007) The prospective association of general and central obesity variables with incident type 2 diabetes in adults, Tehran lipid and glucose study. Diabetes Res Clin Pract 76, 449-454.

27. Mansour AA \& Al-Jazairi MI (2007) Cut-off values for anthropometric variables that confer increased risk of type 2 diabetes mellitus and hypertension in Iraq. Arch Med Res 38, 253-258.

28. Akpinar E, Bashan I, Bozdemir N \& Saatci E (2007) Which is the best anthropometric technique to identify obesity: body mass index, waist circumference or waist-hip ratio? Coll Antropol 31, 387-393.

29. Onat A, Sansoy V \& Uysal O (1999) Waist circumference and waist-to-hip ratio in Turkish adults: interrelation with other risk factors and association with cardiovascular disease. Int J Cardiol 70, 43-50.

30. Onat A, Ceyhan K, Basar O, Erer B, Toprak S \& Sansoy V (2002) Metabolic syndrome: major impact on coronary risk in a population with low cholesterol levels - a prospective and cross-sectional evaluation. Atherosclerosis $\mathbf{1 6 5}$, 285-292.

31. Mahley RW, Palaoglu KE, Atak Z et al. (1995) Turkish Heart Study: lipids, lipoproteins, and apolipoproteins. J Lipid Res 36, 839-859.

32. Mahley RW, Can S, Ozbayrakci S, Bersot TP, Tanir S, Palaoglu KE \& Pepin GM (2005) Modulation of highdensity lipoproteins in a population in Istanbul, Turkey, with low levels of high-density lipoproteins. Am J Cardiol 96, 547-555.

33. Can AS \& Bersot TP (2007) Analysis of agreement among definitions of metabolic syndrome in nondiabetic Turkish adults: a methodological study. BMC Public Health 7, 353.

34. World Medical Association (2004) World Medical Association Declaration of Helsinki. Ethical Principles for Medical Research Involving Human Subjects. http://www.wma.net/ e/policy/pdf/17c.pdf.

35. Friedewald WT, Levy RI \& Fredrickson DS (1972) Estimation of the concentration of low-density lipoprotein cholesterol in plasma, without use of the preparative ultracentrifuge. Clin Chem 18, 499-502.

36. Matthews DR, Hosker JP, Rudenski AS, Naylor BA, Treacher DF \& Turner RC (1985) Homeostasis model assessment: insulin resistance and $\beta$-cell function from fasting plasma glucose and insulin concentrations in man. Diabetologia 28, 412-419.

37. Grundy SM, Cleeman JI, Daniels SR et al.; American Heart Association; National Heart, Lung, and Blood Institute (2005) Diagnosis and management of the metabolic syndrome: an American Heart Association/National Heart, Lung, and Blood Institute Scientific Statement. Circulation 112, 2735-2752.

38. Berry JD, Lloyd-Jones DM, Garside DB \& Greenland P (2007) Framingham risk score and prediction of coronary heart disease death in young men. Am Heart J 154, 80-86.

39. Koller MT, Steyerberg EW, Wolbers M, Stijnen T, Bucher HC, Hunink MG \& Witteman JC (2007) Validity of the Framingham point scores in the elderly: results from the Rotterdam study. Am Heart J 154, 87-93.

40. Chobanian AV, Bakris GL, Black HR et al.; National Heart, Lung, and Blood Institute Joint National Committee on
Prevention, Detection, Evaluation, and Treatment of High Blood Pressure; National High Blood Pressure Education Program Coordinating Committee (2003) The Seventh Report of the Joint National Committee on Prevention, Detection, Evaluation, and Treatment of High Blood Pressure: the JNC 7 report. JAMA 289, 2560-2572.

41. Expert Committee on the Diagnosis and Classification of Diabetes Mellitus (2003) Report of the expert committee on the diagnosis and classification of diabetes mellitus. Diabetes Care 26, Suppl. 1, S5-S20.

42. Malik S, Wong ND, Franklin SS, Kamath TV, L'Italien GJ, Pio JR \& Williams GR (2004) Impact of the metabolic syndrome on mortality from coronary heart disease, cardiovascular disease, and all causes in United States adults. Circulation 110, 1245-1250.

43. Altman D (1991) Practical Statistics for Medical Research. London: Chapman-Hall.

44. Dawson-Saunders B \& Trapp R (editors) (1994) Basic \& Clinical Biostatistics. East Norwalk, CT: Appleton \& Lange.

45. DeLong ER, DeLong DM \& Clarke-Pearson DL (1988) Comparing the areas under two or more correlated receiver operating characteristic curves: a nonparametric approach. Biometrics 44, 837-845.

46. Lemieux S, Prud'homme D, Bouchard C, Tremblay A \& Despres JP (1996) A single threshold value of waist girth identifies normal-weight and overweight subjects with excess visceral adipose tissue. Am J Clin Nutr 64, 685-693.

47. Klein S, Allison DB, Heymsfield SB, Kelley DE, Leibel RL, Nonas C \& Kahn R (2007) Waist circumference and cardiometabolic risk: a consensus statement from Shaping America's Health: Association for Weight Management and Obesity Prevention; NAASO, The Obesity Society; the American Society for Nutrition; and the American Diabetes Association. Am J Clin Nutr 85, 1197-1202.

48. Smith SR, Lovejoy JC, Greenway F, Ryan D, deJonge L, de la Bretonne J, Volafova J \& Bray GA (2001) Contributions of total body fat, abdominal subcutaneous adipose tissue compartments, and visceral adipose tissue to the metabolic complications of obesity. Metabolism 50, 425-435.

49. Snijder MB, Dekker JM, Visser M, Bouter LM, Stehouwer CD, Kostense PJ, Yudkin JS, Heine RJ, Nijpels G \& Seidell JC (2003) Associations of hip and thigh circumferences independent of waist circumference with the incidence of type 2 diabetes: the Hoorn Study. Am J Clin Nutr 77, 1192-1197.

50. Uretsky S, Messerli FH, Bangalore S, Champion A, CooperDehoff RM, Zhou Q \& Pepine CJ (2007) Obesity paradox in patients with hypertension and coronary artery disease. Am J Med 120, 863-870.

51. Romero-Corral A, Montori VM, Somers VK, Korinek J, Thomas RJ, Allison TG, Mookadam F \& Lopez-Jimenez F (2006) Association of bodyweight with total mortality and with cardiovascular events in coronary artery disease: a systematic review of cohort studies. Lancet 368, 666-678.

52. Franzosi MG (2006) Should we continue to use BMI as a cardiovascular risk factor? Lancet 368, 624-625.

53. Yu Y, Wyszynski DF, Waterworth DM et al. (2005) Multiple QTLs influencing triglyceride and HDL and total cholesterol levels identified in families with atherogenic dyslipidemia. J Lipid Res 46, 2202-2213.

54. Seidell JC, Perusse L, Despres JP \& Bouchard C (2001) Waist and hip circumferences have independent and opposite effects on cardiovascular disease risk factors: the Quebec Family Study. Am J Clin Nutr 74, 315-321.

55. Kuk JL, Janiszewski PM \& Ross R (2007) Body mass index and hip and thigh circumferences are negatively associated with visceral adipose tissue after control for waist circumference. Am J Clin Nutr 85, 1540-1544.

56. Schooling CM, Thomas GN, Leung GM, Ho SY, Janus ED \& Lam TH (2007) Is height associated with cardiovascular risk in Chinese adults? Epidemiology 18, 274-278. 
57. McCarron P, Okasha M, McEwen J \& Smith GD (2002) Height in young adulthood and risk of death from cardiorespiratory disease: a prospective study of male former students of Glasgow University, Scotland. Am J Epidemiol 155, 683-687.

58. Republic of Turkey Ministry of Internal Affairs Department of Population and Citizenship (2003) Population Statistics. http://www.nvi.gov.tr/Hizmetler/IstatistiklerNufus_kutukleri_ statistikleri.html/
59. Ozsahin AK, Gokcel A, Sezgin N, Akbaba M, Guvener N, Ozisik L \& Karademir BM (2004) Prevalence of the metabolic syndrome in a Turkish adult population. Diabetes Nutr Metab 17, 230-234.

60. Sanisoglu SY, Oktenli C, Hasimi A, Yokusoglu M \& Ugurlu $M$ (2006) Prevalence of metabolic syndrome-related disorders in a large adult population in Turkey. BMC Public Health 6, 92. 